\title{
Diamond synthesis at high filament temperature
}

\section{D.M. LI, T. MÄNTILÄ and J. LEVOSKA*}

Institute of Materials Science, Tampere University of Technology, P.O. Box 589, 33101 Tampere, Finland * Microelectronics and Material Physics Laboratories, University of Oulu, P.O. Box 400, 90571 Oulu, Finland

\begin{abstract}
Diamond particles and films have been deposited on silicon wafer by using hot filament assisted chemical vapour deposition (HFCVD). Tantalum carbide filaments were used in the temperature range of $2700-2890^{\circ} \mathrm{C}$. The filament can be repeatedly used for diamond deposition in $\mathrm{CH}_{4} / \mathrm{H}_{2} / \mathrm{O}_{2}$ atmosphere without deformation in its geometry. Diamond structure was deposited at high methane concentration up to $12 \%$ at filament temperature of $2890^{\circ} \mathrm{C}$. By introducing $5.6 \%$ of oxygen, the methane concentration can be extended to $16 \%$. Diamond particles and films were characterized by scanning electron microscopy (SEM), X-ray diffraction (XRD) and Raman spectroscopy.
\end{abstract}

